\title{
Imagens do futebol
}




\section{Futebol e arte: o G-Onze, um time de craques}

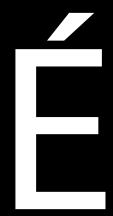

com grande alegria que finalizamos nosso dossiê "Futebol" com um ensaio de imagens de artistas que fazem a história da arte contemporânea do Brasil. Todas integram o trabalho de um grupo que se intitula G-Onze, Associação para o Desenvolvimento da Arte e da Cultura, com curadoria e presidência de Ivald Granato. Por que G-Onze? Ora, pelos onze jogadores que compõem um time de futebol.

O grupo surgiu de forma peculiar. Em 2003, Granato estava fazendo uma exposição em Berlim e recebeu a visita do embaixador brasileiro, que Ihe perguntou se, juntamente com um ou dois artistas tupiniquins, não poderiam pensar numa mostra com vistas à Copa do Mundo que aconteceria em 2006 na Alemanha.

Ora, a ideia não era assim tão nova. Em 1998 havia acontecido na França, intitulado "Cultura no Futebol', por ocasião de sua Copa, um grande evento de artes plásticas com artistas do mundo todo, inclusive com participação do próprio Granato.

Ivald gostou da ideia. Na volta conversou sobre o assunto com seus amigos Rubens Gerchman e Cláudio Tozzi - que também já haviam pintado as cores e a emoções do nosso futebol. E chegaram à conclusão de que o empreendimento deveria ser uma coisa mais abrangente. Decidiram convidar outros artistas para participar.

Foi assim que surgiu em 2003 o G-Onze. Além da bem-sucedida exposição na Alemanha em 2006, o grupo protagonizou outra mostra de peso na África do Sul, em 2010 - esta, uma via de mão dupla, com autores de ambos os países.
Para este 2014, o G-Onze pensa em tirar a arte dos museus e levá-la para logradouros públicos - praças, entornos de estádios que receberão a Copa aqui - para uma maior disseminação das artes plásticas no país. Se o assunto é futebol, todos estarão "ligados", observa Ivald. Isso, antes de o evento ter início, pois, como diz o próprio Granato - e sabemos nós -, depois que a bola estiver rolando no mundial, que arte, que nada!

Para o evento da Copa do Brasil, como nas vezes anteriores, alguns artistas participarão e outros serão substituídos, como ocorreu nas duas mostras anteriores, mas a "coluna dorsal" do movimento continuará a mesma. O momento atual é de aprovação de projetos e de captação de recursos. De toda forma, não há dúvida de que o G-Onze, pela envergadura de seus componentes, apresentará um trabalho de craques. Pois, como diz Ivald Granato, já se foi o tempo em que o tema "futebol" nas artes plásticas era visto com preconceito. Finalizamos, com o artista: "A variação de temas que o futebol pode propiciar é imensa, desde a torcida até a gestualidade dos jogadores. É um tema cativante, que emociona".

Nós, da Revista USP, estamos mesmo é muito felizes por fecharmos o nosso dossiê "Futebol" com chave de ouro. E agradecemos imensamente a Granato pela generosidade com que nos cedeu as imagens que tão bem expressam a paixão do brasileiro pelo futebol. Imagens tocantes que $o$ leitor poderá apreciar nas próximas páginas.

Francisco Costa 


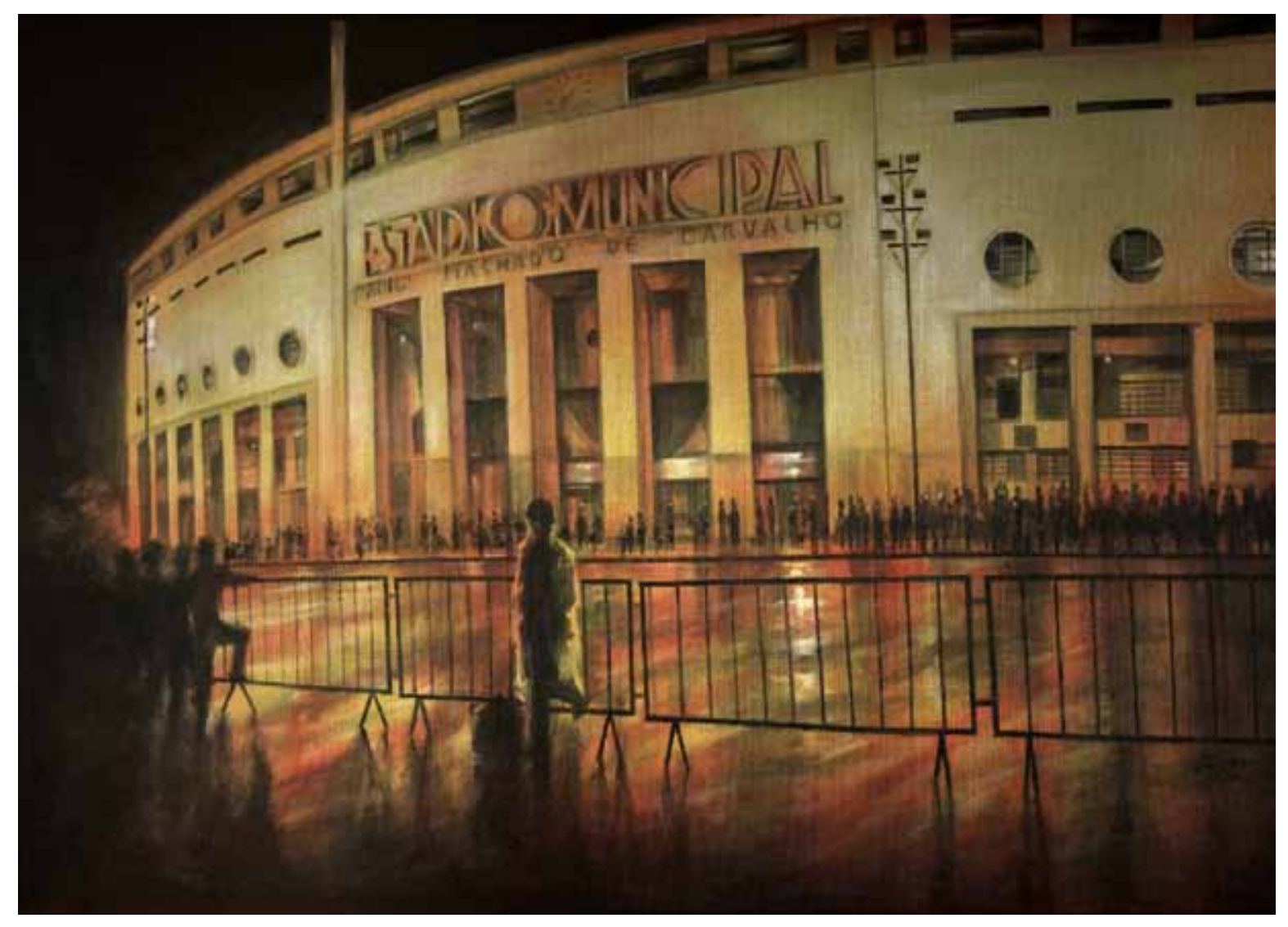

Gregório Gruber,

Pacaembu, 2008,

acrílico sobre tela,

$100 \times 140 \mathrm{~cm}$ 


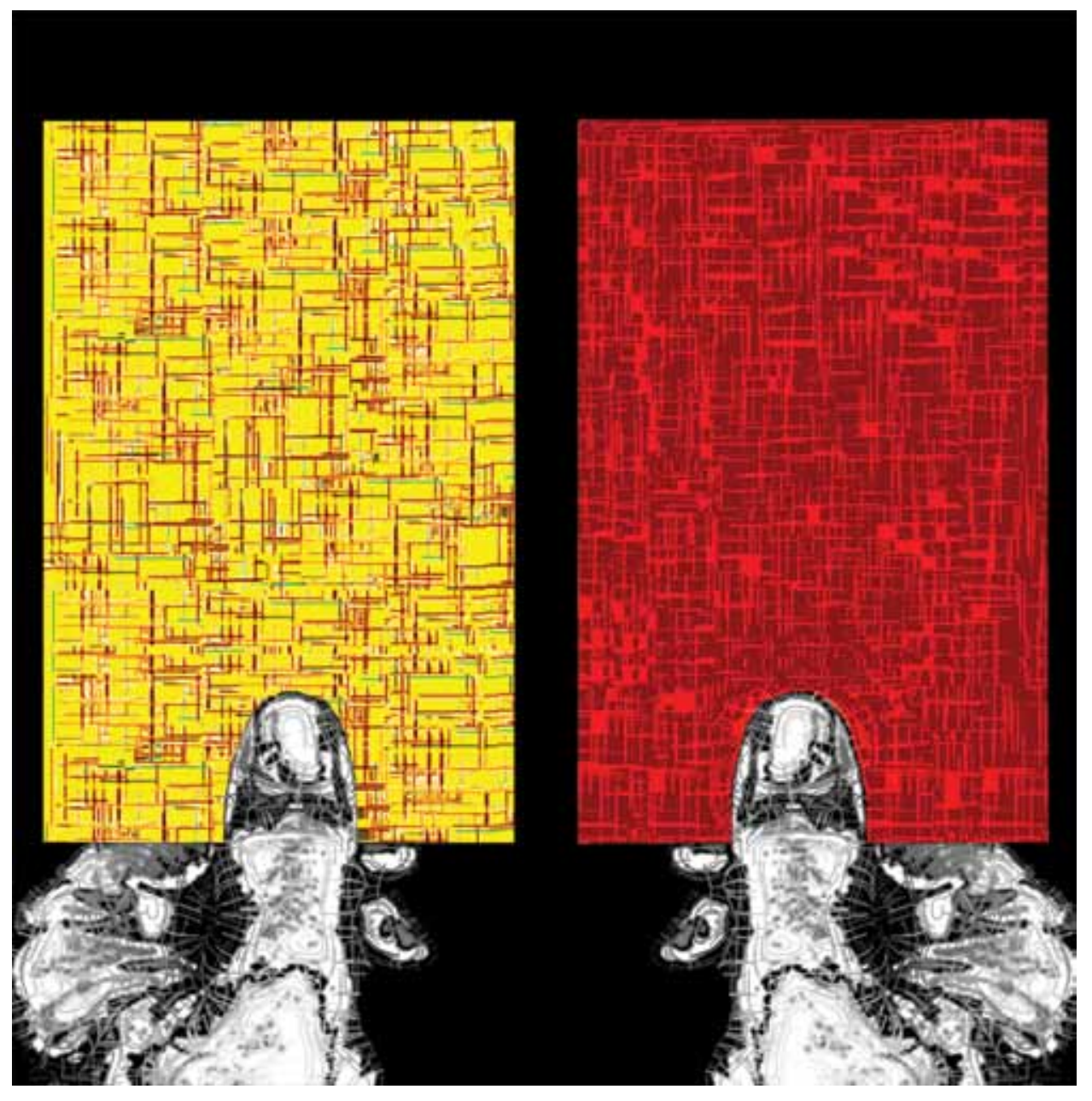

Jô Soares,

Cartões, 2006,

digicromia ou giclée print

em canvas, $200 \times 200 \mathrm{~cm}$ 


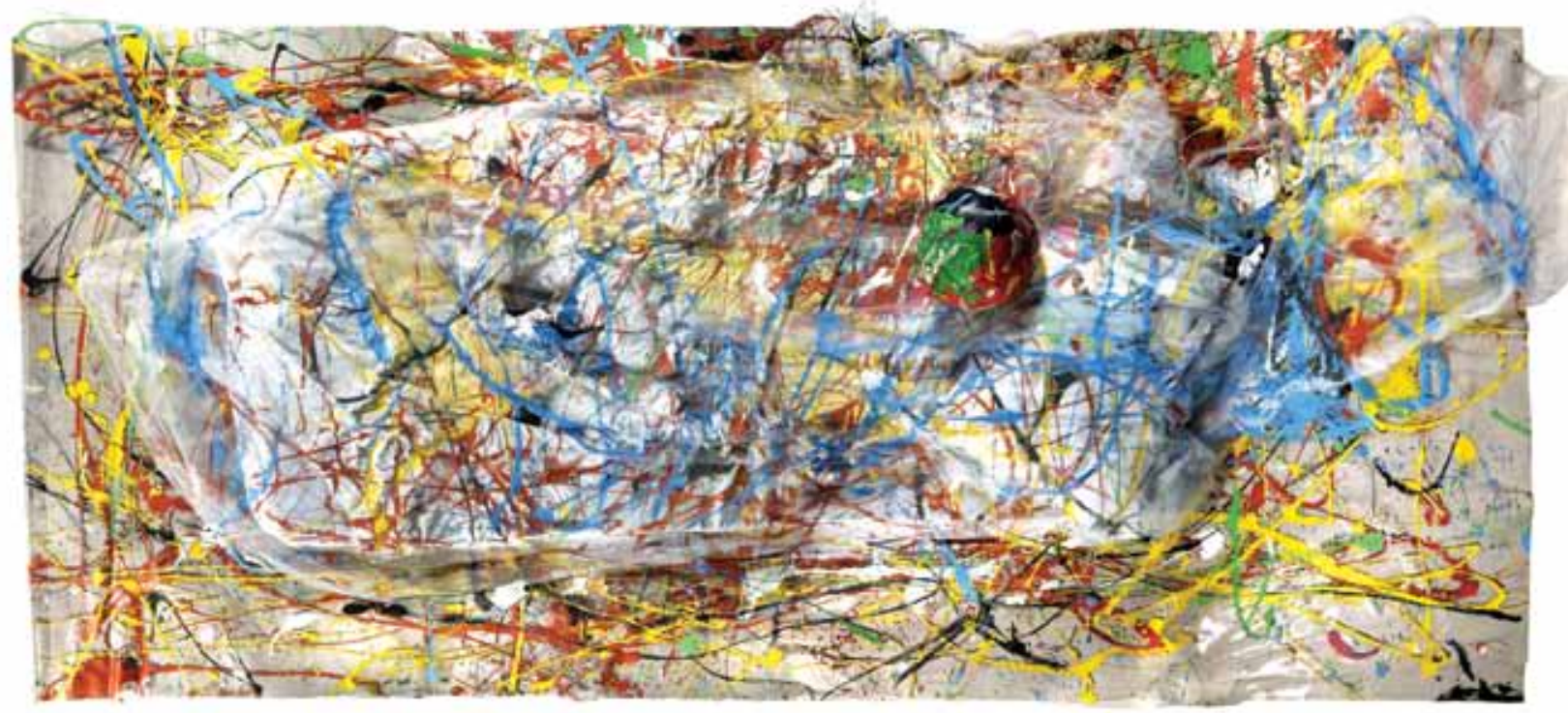

José Roberto Aguilar,

Sonho de uma Bola de Futebol,

2010, técnica mista,

$110 \times 300 \mathrm{~cm}$ 


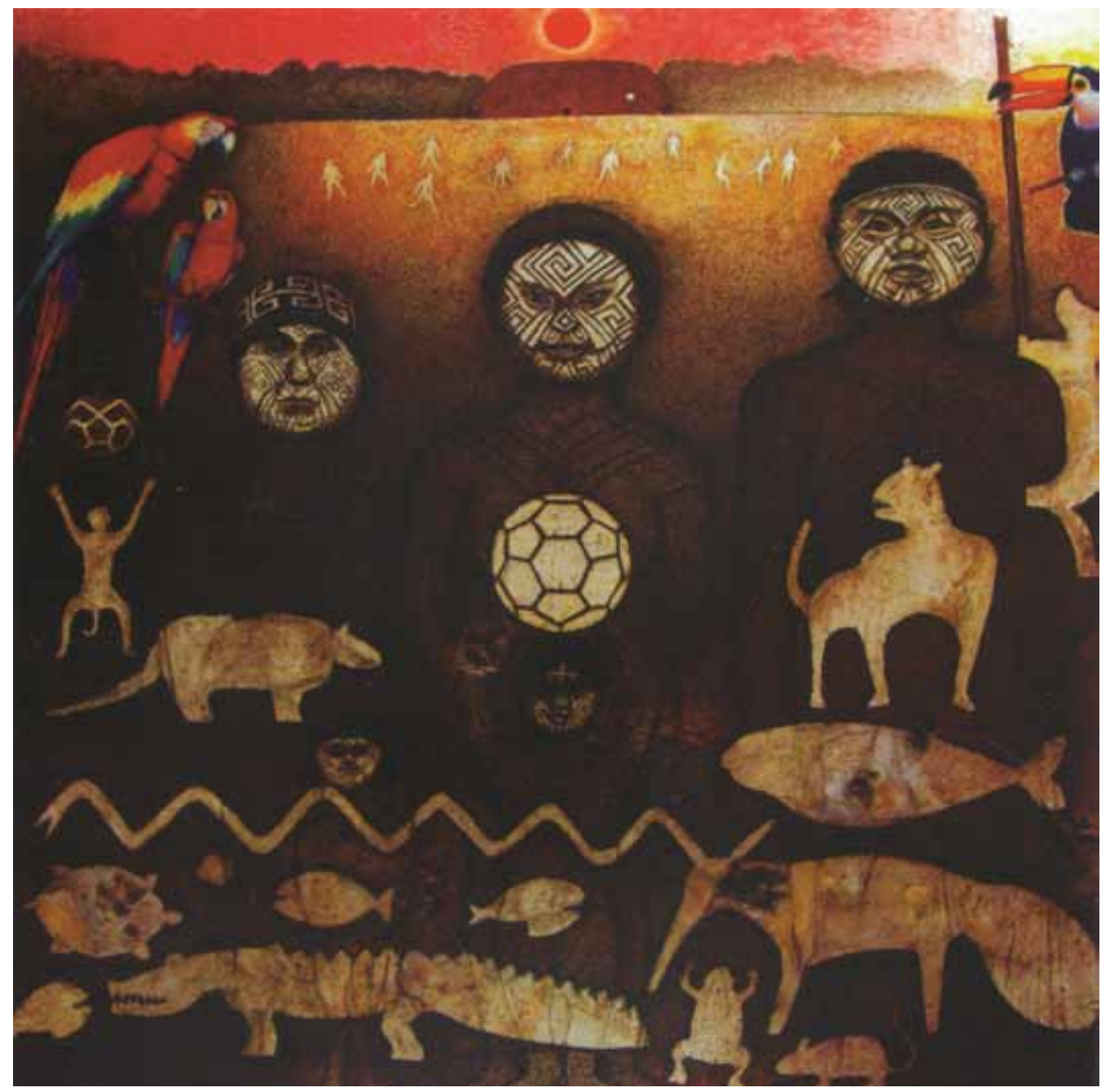

Tomoshige Kusuno,

As Bolas, 2006,

pastel seco sobre papel sobre tela,

$180 \times 180 \mathrm{~cm}$ 


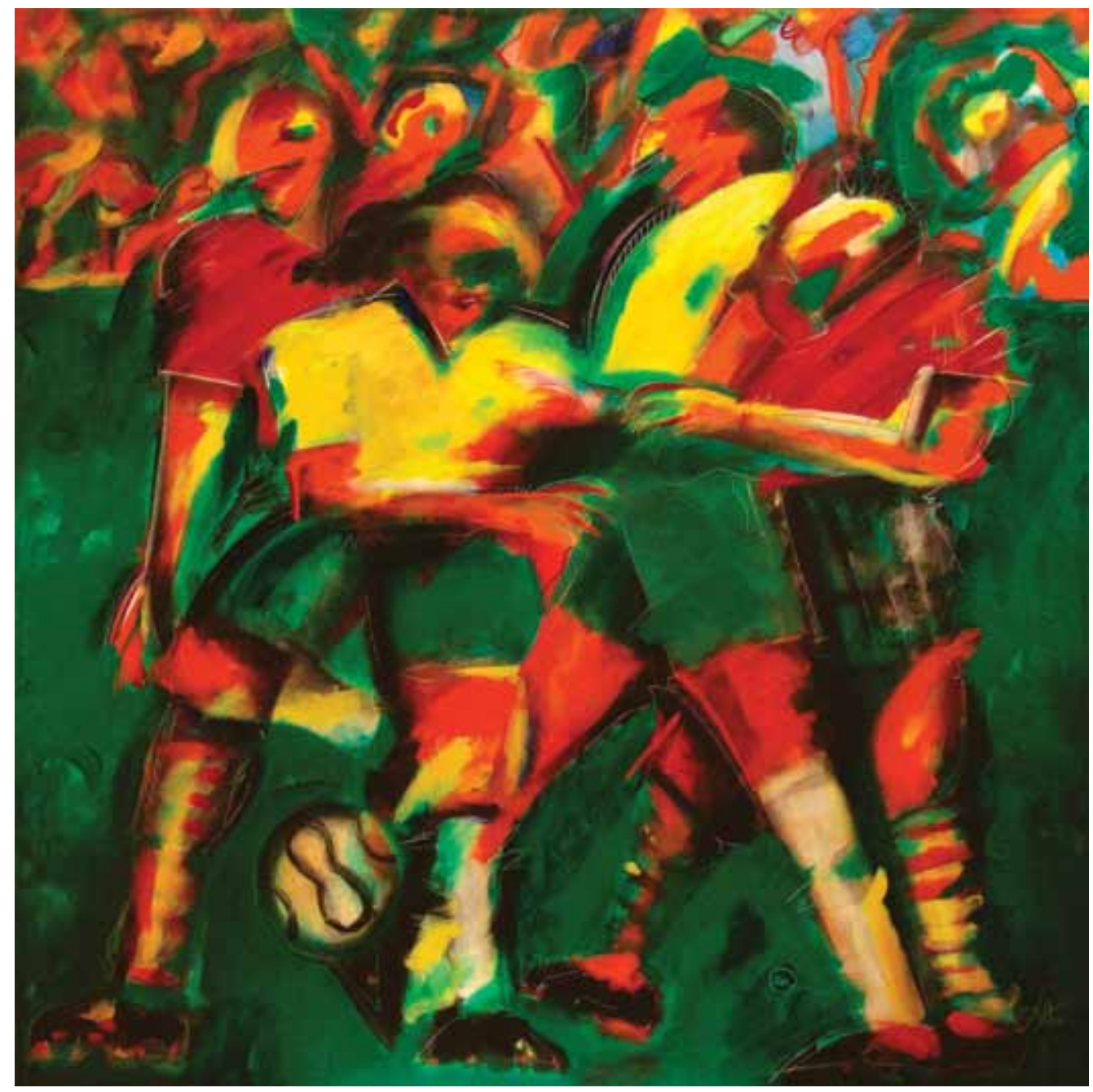

Ivald Granato,

Lance, 2006,

acrílico sobre tela,

$180 \times 180 \mathrm{~cm}$ 
Dossiê/Arte Futebol

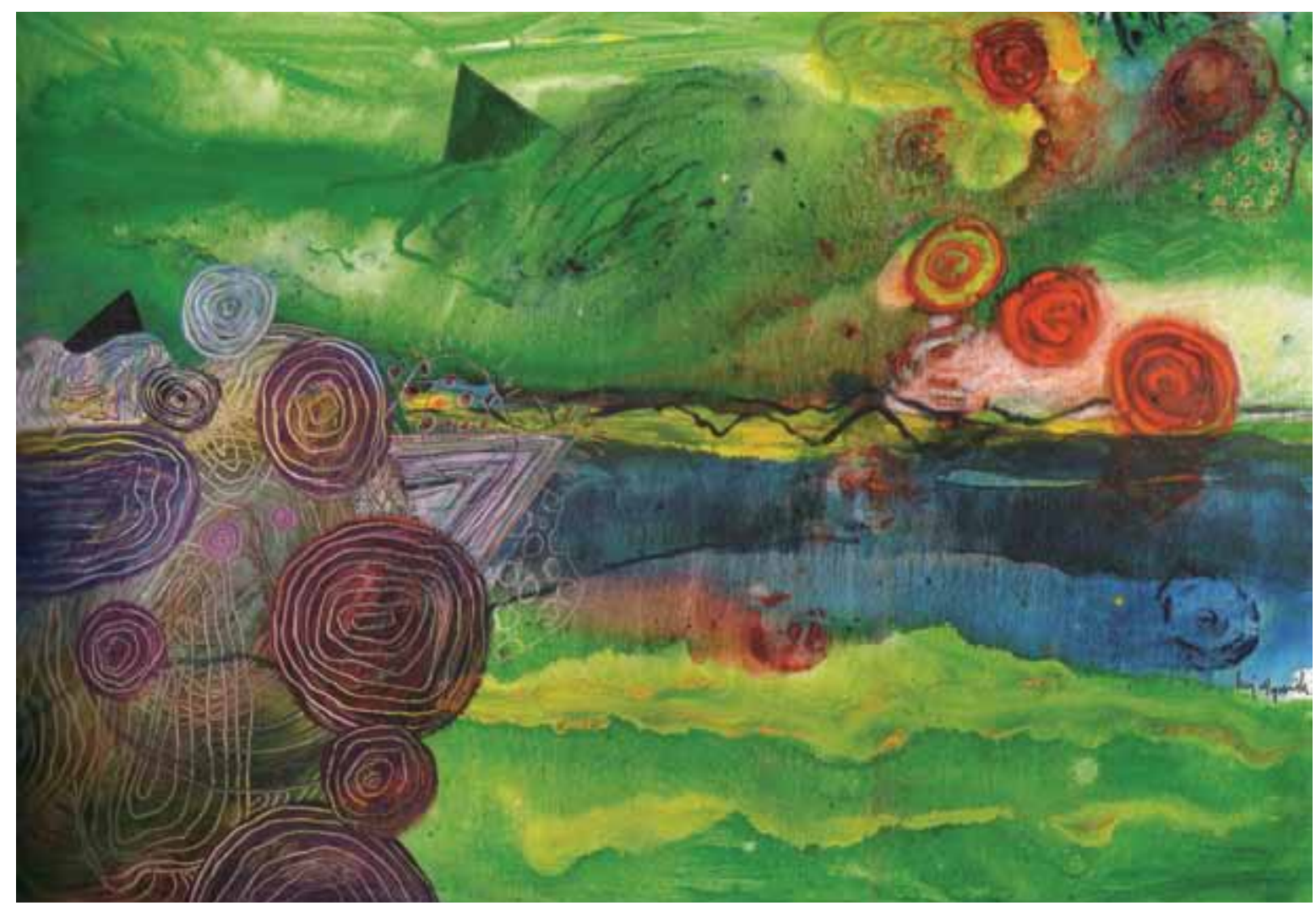

Luiz Áquila,

A Pintura e Seus Movimentos, 2010, acrílico e bastão a óleo sobre tela, $100 \times 140 \mathrm{~cm}$ 


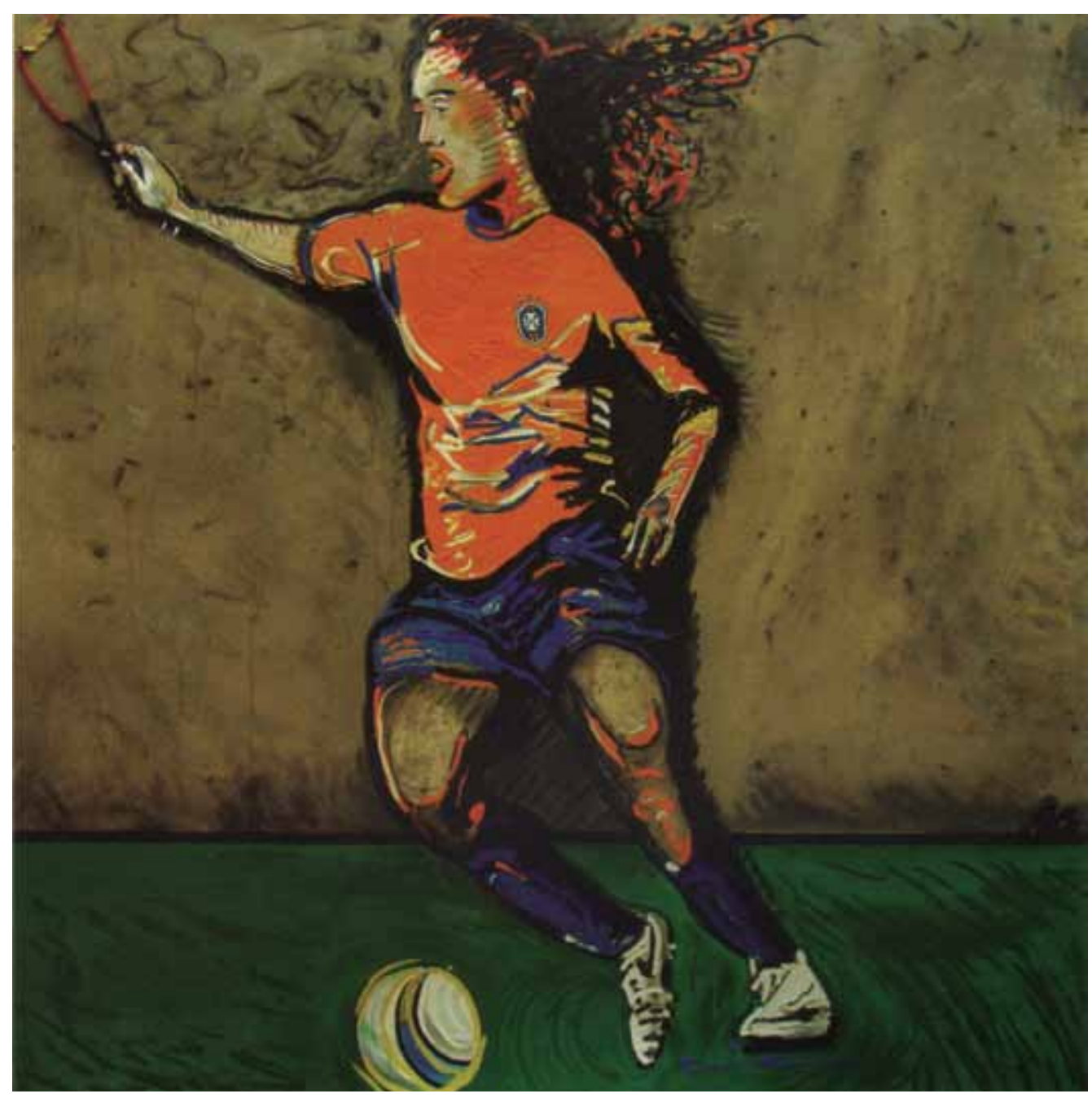

Rubens Gerchman,

Estilingue Ronaldinho, 2006,

acrílico sobre tela,

$200 \times 200 \mathrm{~cm}$ 
Dossiê/Arte Futebol

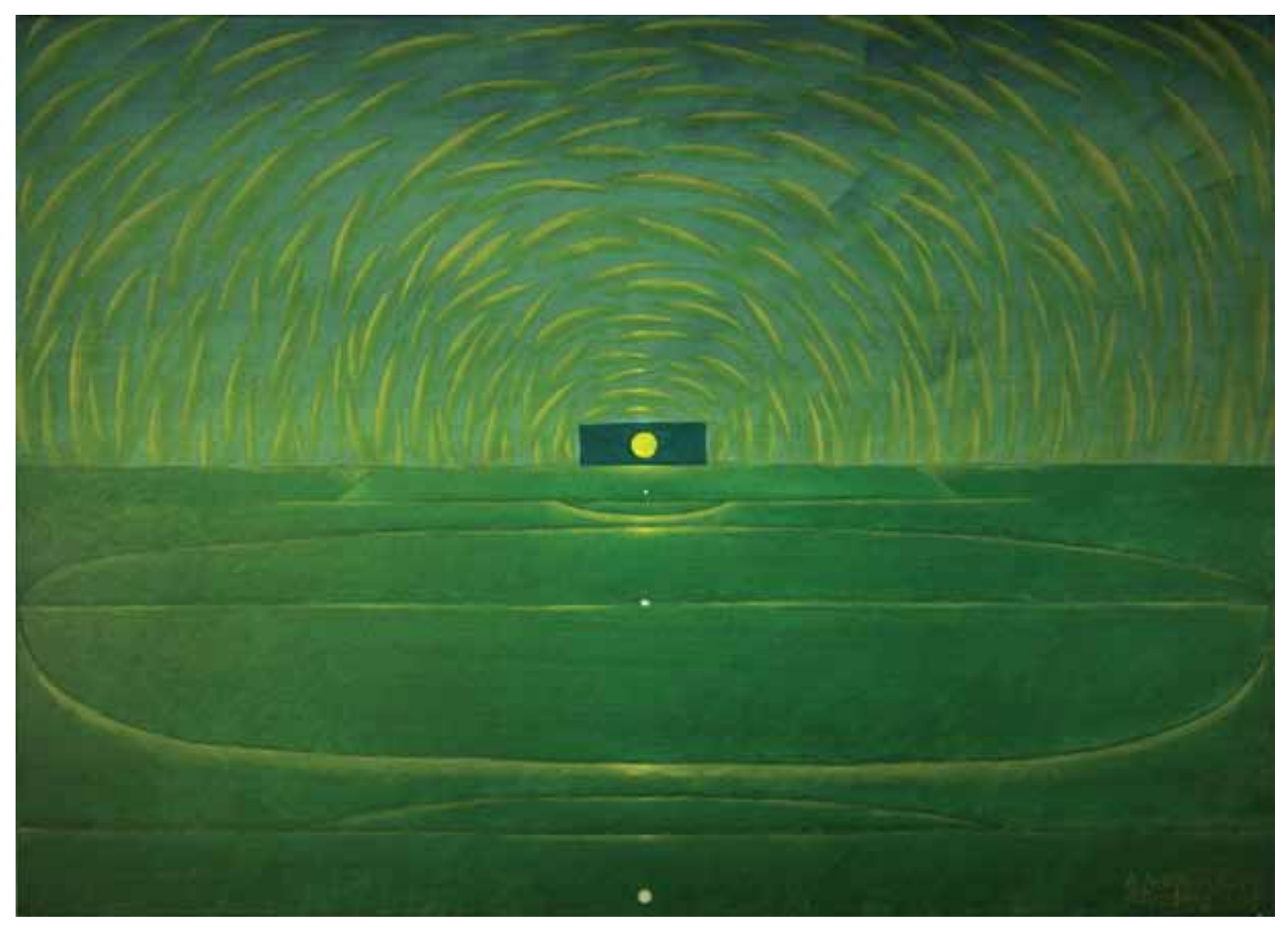

Zélio Alves Pinto,

A Meta, 2010,

acrílico sobre tela,

$100 \times 140 \mathrm{~cm}$ 


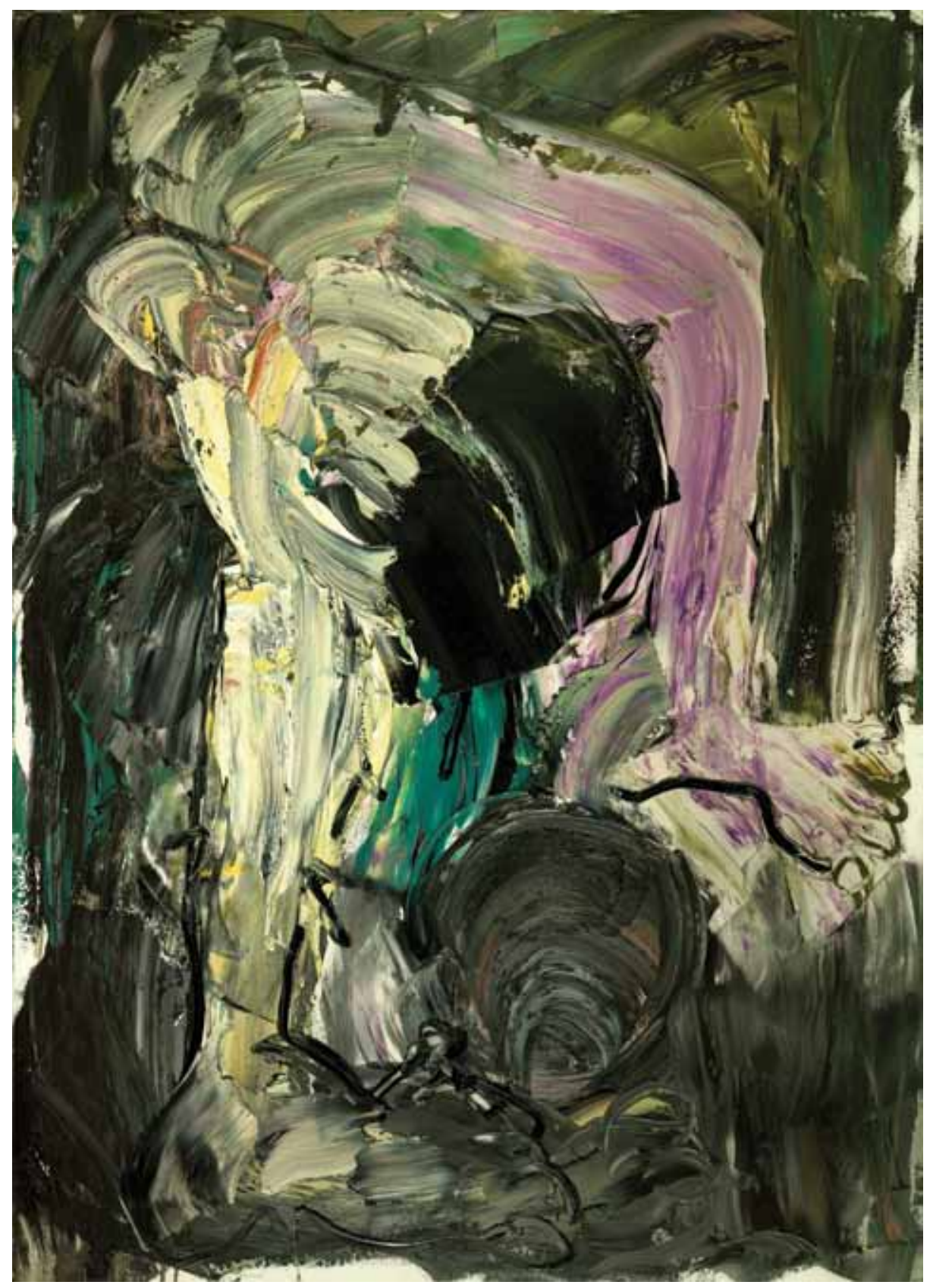

António Hélio Cabral,

Pé na B, 2010,

óleo sobre tela,

$140 \times 100 \mathrm{~cm}$ 


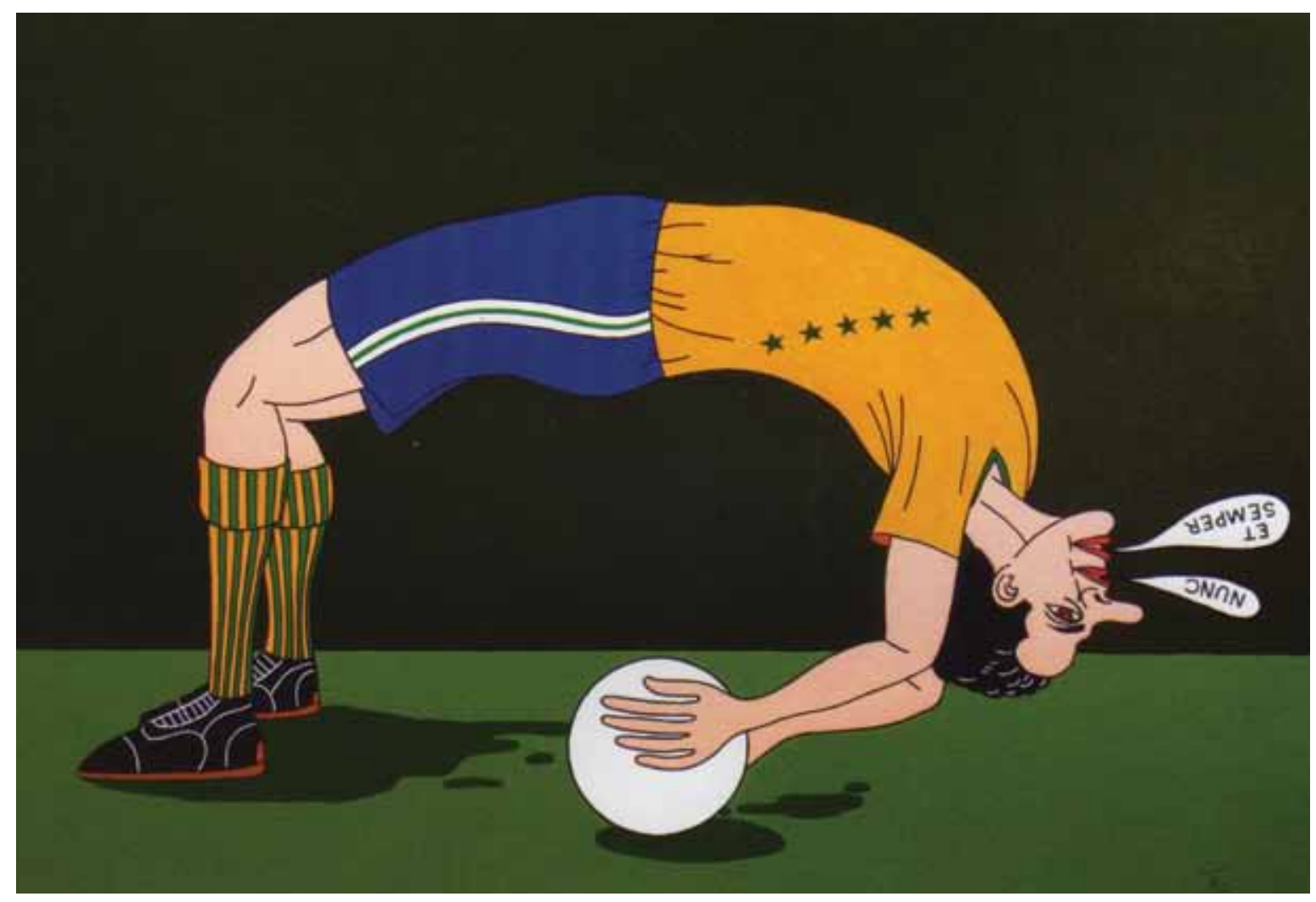

Roberto Magalhães,

Agora e Sempre, 2006, acrílico sobre tela,

$120 \times 200 \mathrm{~cm}$ 


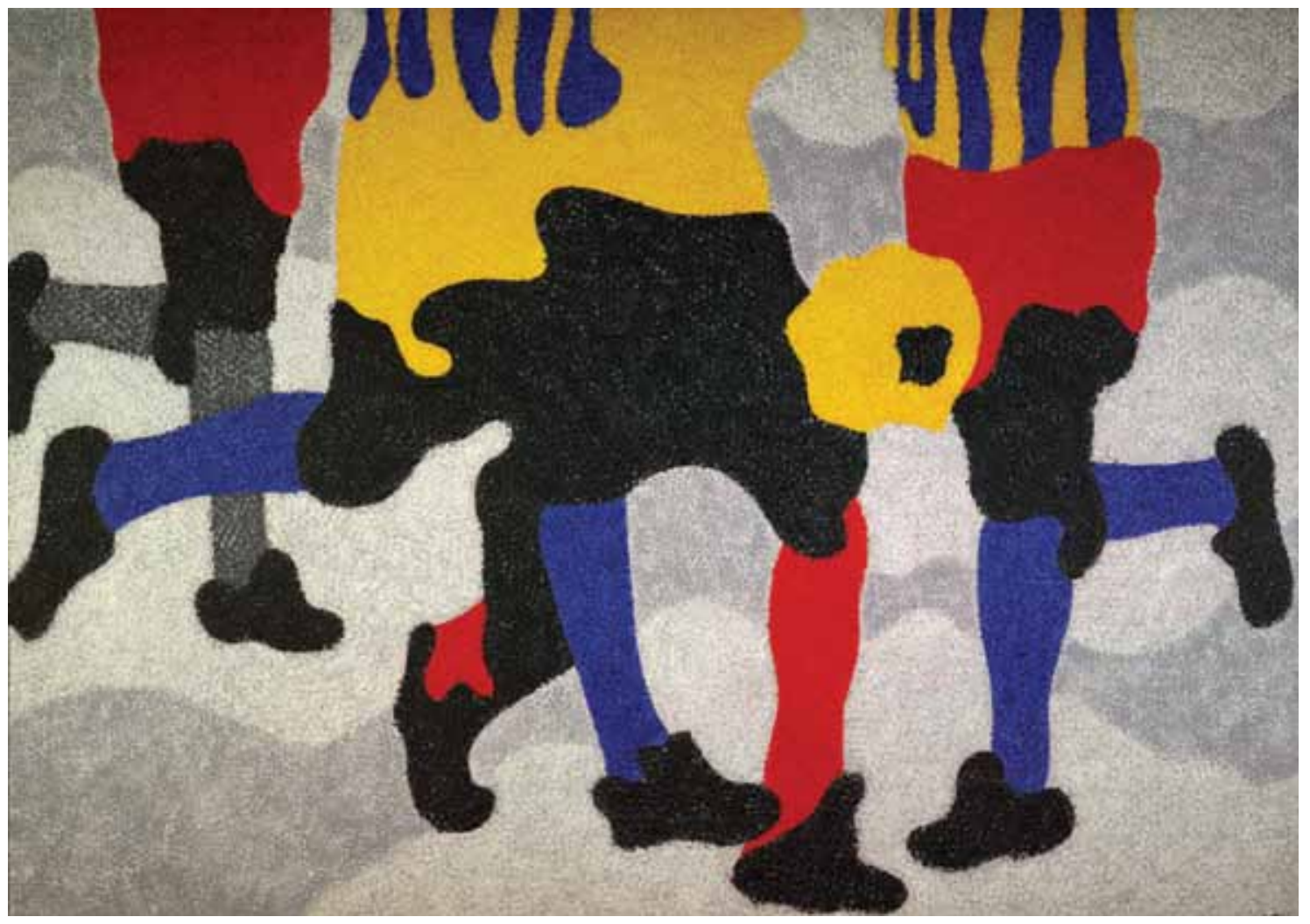

Cláudio Tozzi,

Dança do Futebol, 2010,

acrílico sobre tela colada sobre madeira,

$100 \times 140 \mathrm{~cm}$ 
Dossiê/Arte Futebol

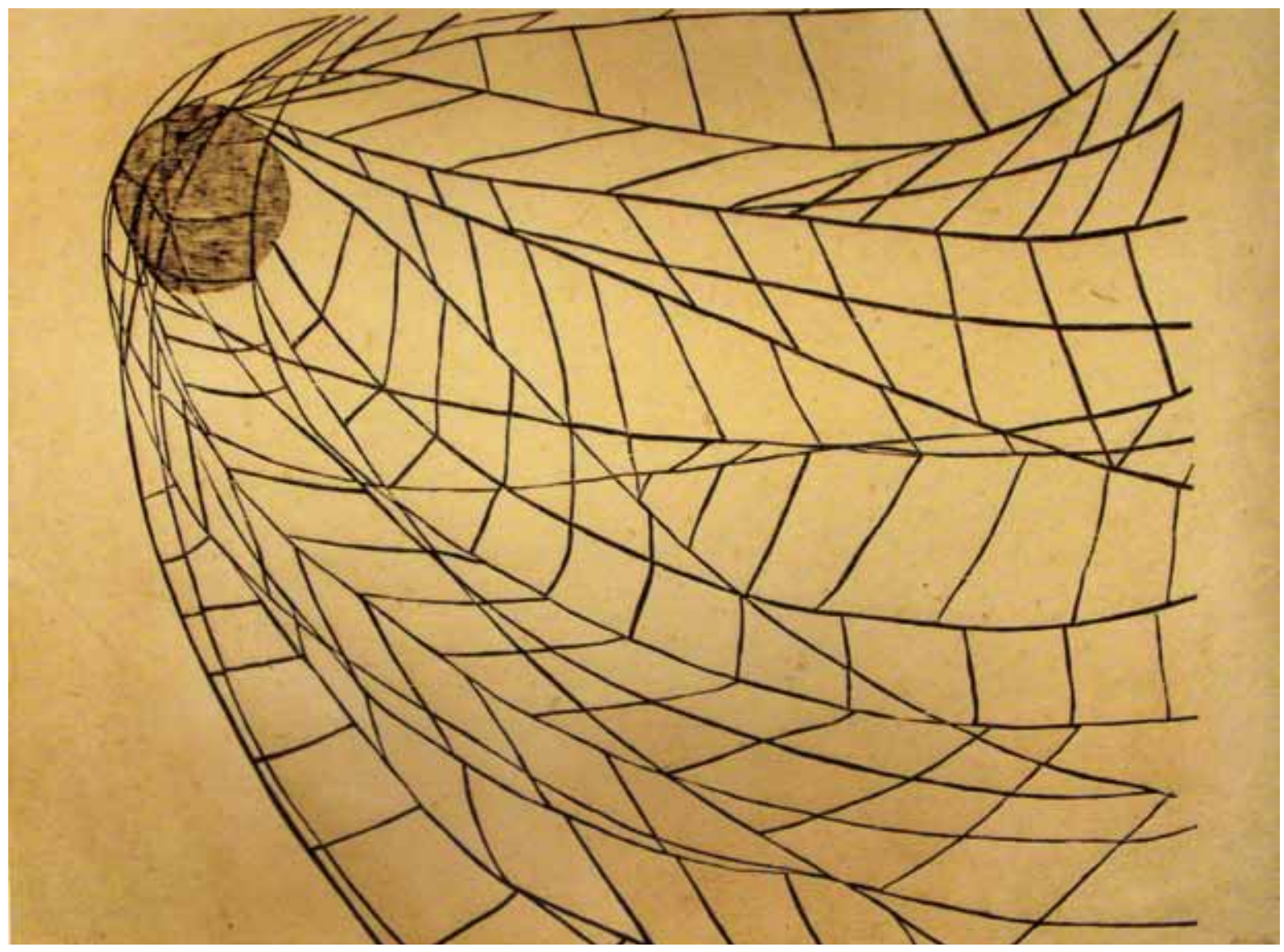

Maria Bonomi,

Gool!, 2006,

xilogravura,

$150 \times 200 \mathrm{~cm}$ 


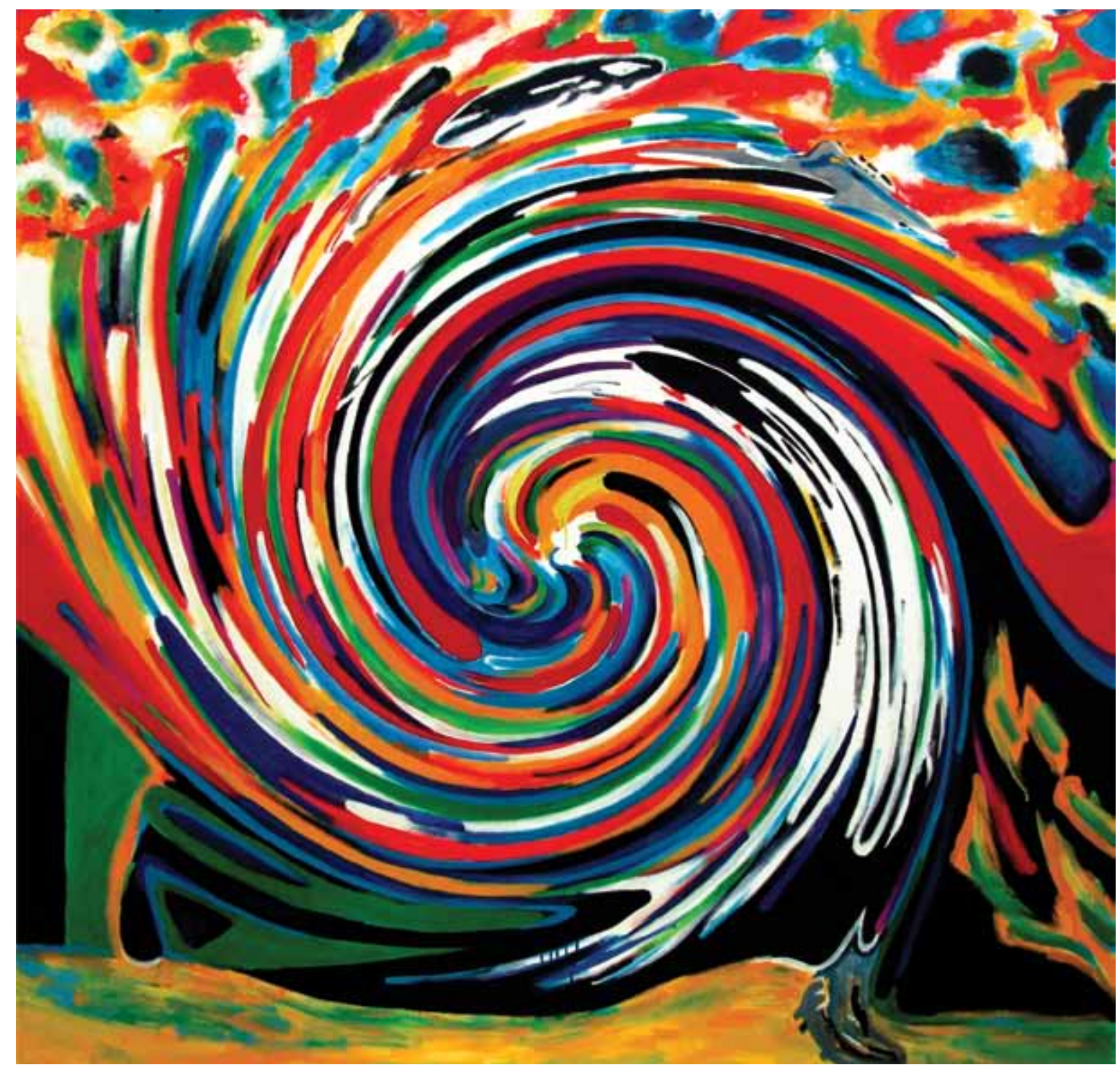

Antonio Peticov,

Bicicleta \#4,

acrílico sobre tela,

$180 \times 180 \mathrm{~cm}$ 


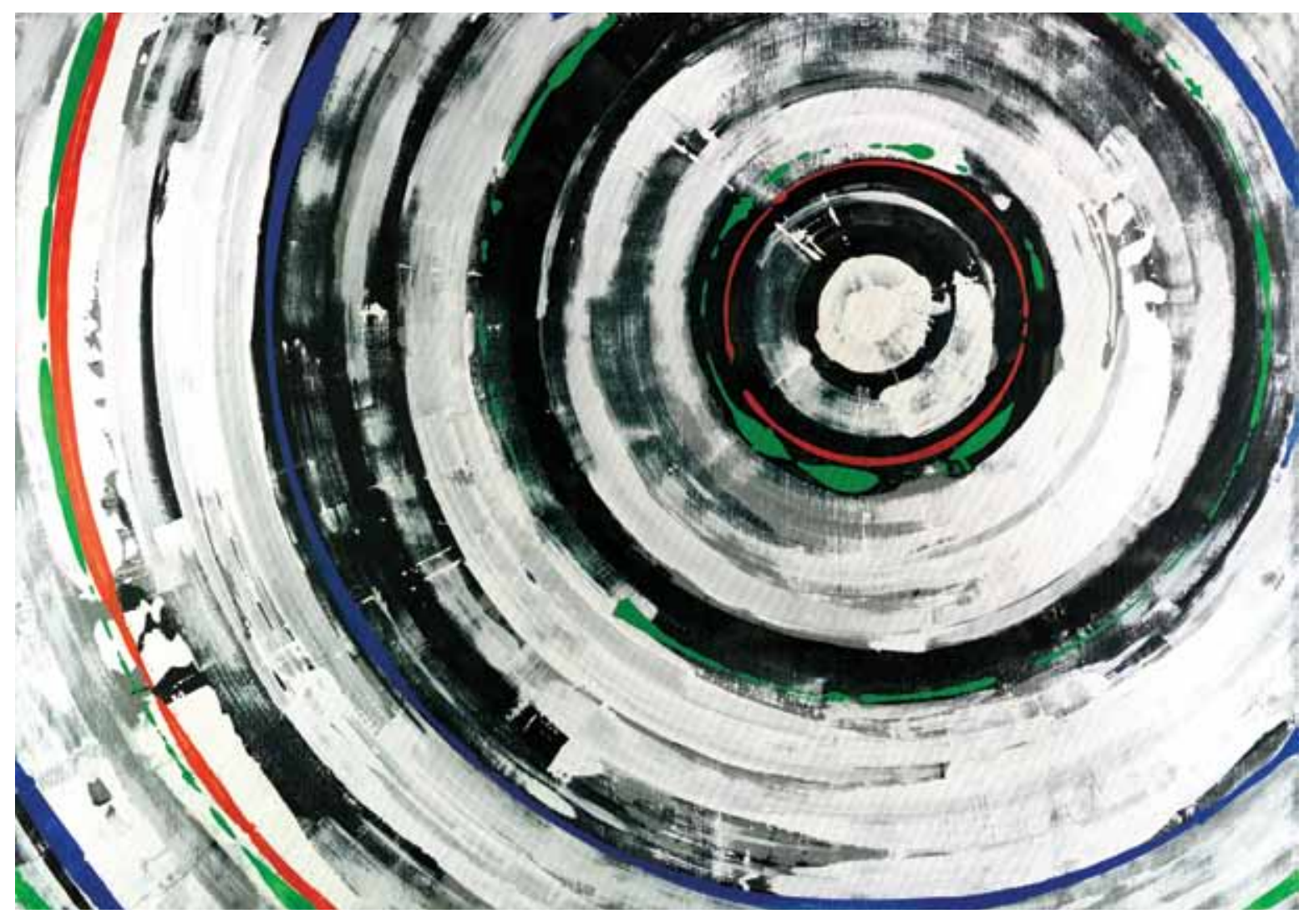

Luiz Paulo Baravelli,

O que o Goleiro Vê, 2010,

acrílico sobre madeira,

$100 \times 140 \mathrm{~cm}$ 


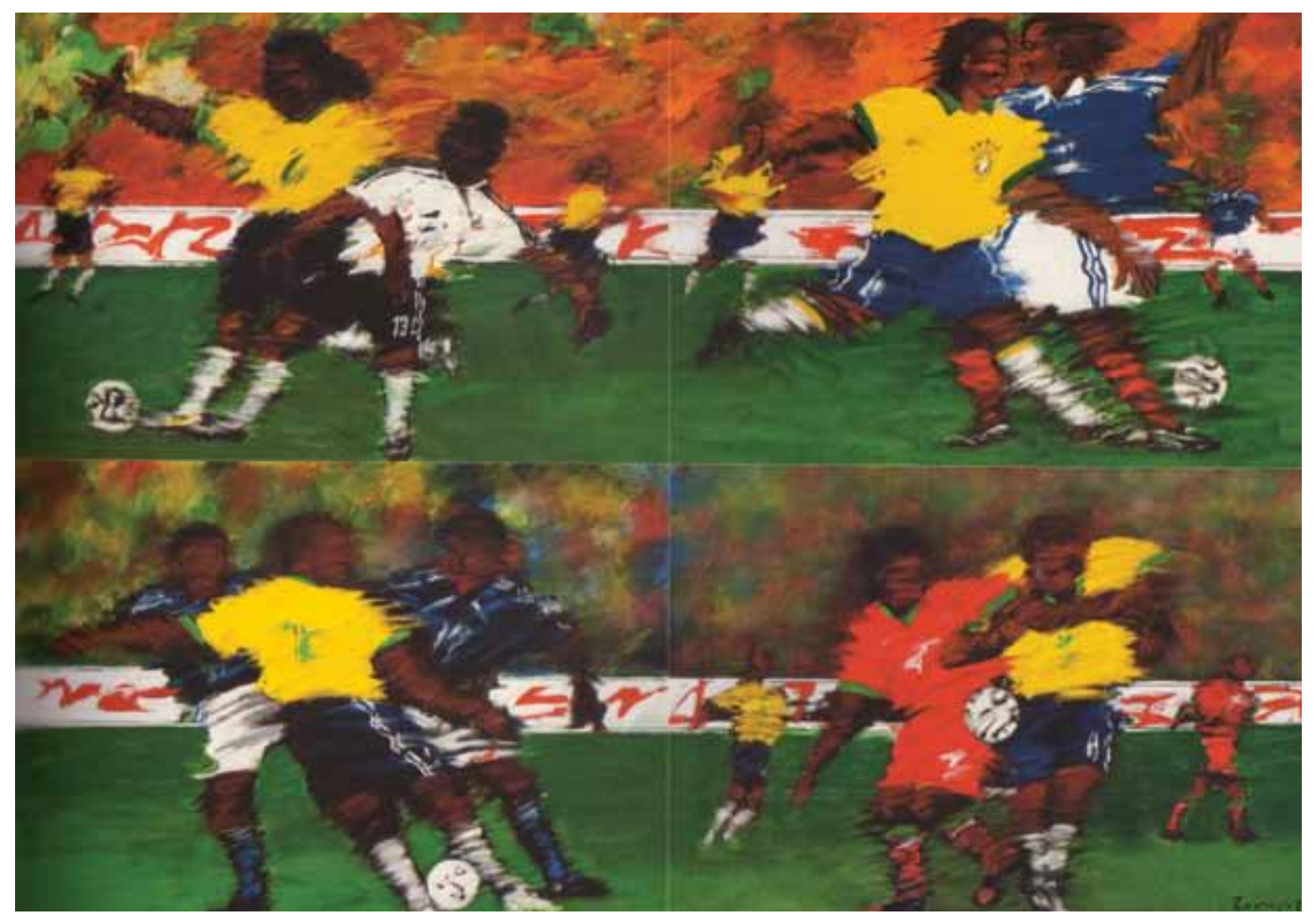

José Zaragoza,

Quadrado Mágico, 2010,

pastel oleoso sobre impressão digital,

$100 \times 140 \mathrm{~cm}$ 



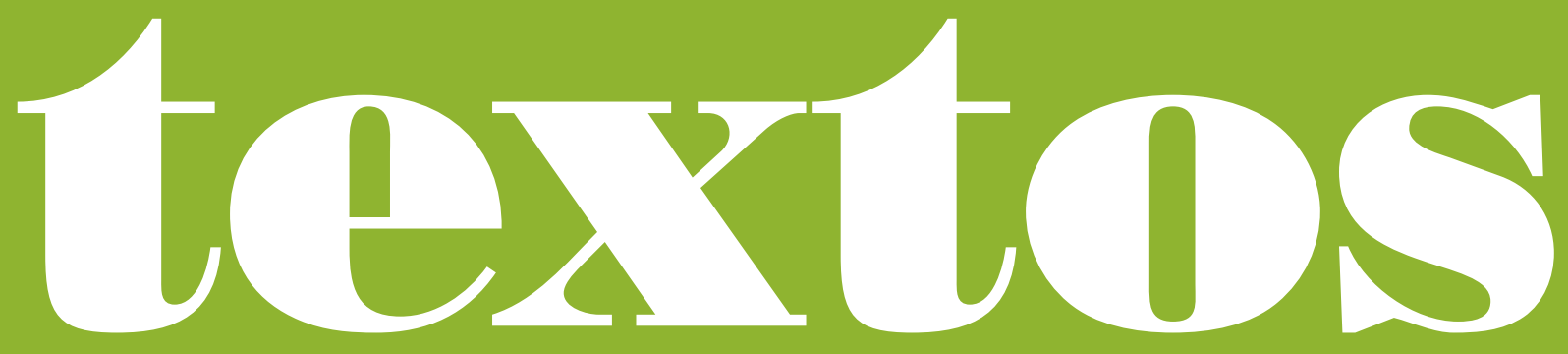

